\title{
Pigmented basal cell carcinoma
}

\author{
John J. S. Martis · Rohan Gatty · K. V. Rajeshwara · Dayanand Jairaj · Sunil Sudharshan
}

Received: 13 February 2009 / Accepted: 18 March 2009

(C) Association of Surgeons of India 2009

A 56-year-old male presented to out-patient department with an ulcer over the scalp following trauma since one year. Ulcer has been increasing in size with bleeding on and off from it for the past 2 months. There was no previous history of environmental or occupational exposure to arsenic, radiation or PUVA therapy. Local examination revealed $2 \times 2 \mathrm{~cm}$ ulcer with pigmented beaded edge on the scalp in the right parietal region (Fig. 1). Ulcer was not adherent to the underlying skull bone. There was no regional lymphadenopathy.

Histopathological examination of the biopsy specimen from the ulcer edge stained with hematoxylin- eosin stain showed islands of basaloid cell proliferation with peripheral palisading. Cells were oval to spindle shaped with mild to moderate pleomorphism, hyperchromasia and frequent atypical mitosis. The basal layer showed increase in melanocytes and melanin deposition (Fig. 2). The melanin pigment was confirmed by positive Fontana-Masson stain. These histopathological features were consistent with pigmented basal cell carcinoma (BCC).

Pigmented $\mathrm{BCC}$ is an uncommon variant of nodular $\mathrm{BCC}$ and it accounts for $6 \%$ of all BCC. This variety has all the features of the basal type and in addition, brown or black pigmentation is seen. The prevalence increases greatly with the exposure to sunlight. Trauma may be a

J. J. S. Martis · R. Gatty · K. V. Rajeshwara · D. Jairaj ·

S. Sudharshan

Department of Surgery,

Fr. Muller Medical College Hospital,

Kankanady, Mangalore - 575 002,

Karnataka, India

J. J. S. Martis ( $\square)$

E-mail: martisjohn@yahoo.co.in

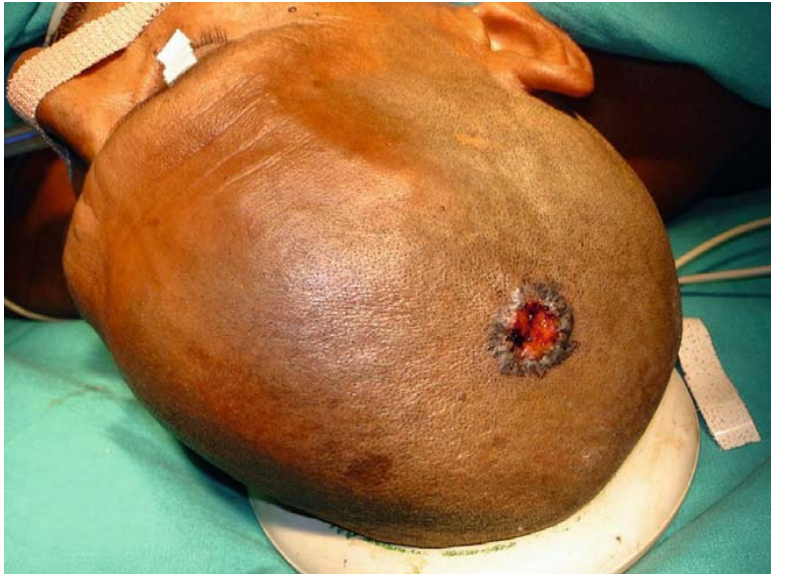

Fig. 1 Ulcer with pigmented beaded edge on the scalp in the right parietal region

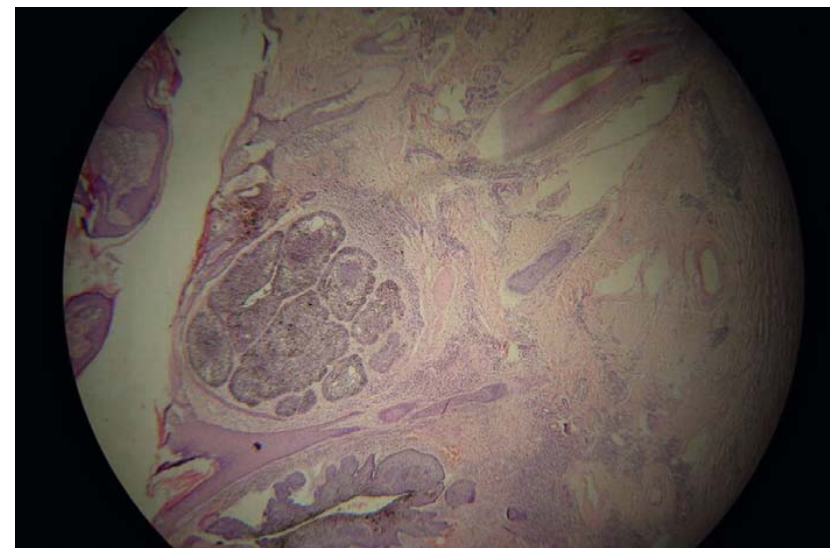

Fig. 2 Microphotograph showing islands of basaloid cell proliferation with peripheral palisading with increase in melanocytes and melanin deposition (Hematoxylin-eosin stain, Magnification $\times 100$ ) 
significant risk factor for $\mathrm{BCC}$ either with actinic damage or alone. BCC caused by arsenic ingestion are often of the pigmented basal cell variety, occur frequently on the trunk. Melanocytes proliferate within the tumour and the melanin they produce cause the tumour to be pigmented.

Treatment modalities of BCC include electrodessication and curettage, cryosurgery, surgical excision, Moh's mi- crographic surgery, laser surgery, radiotherapy and chemotherapy. Moh's micrographic surgery is superior to all other modalities of treatment and demonstrated a recurrence rate of $1 \%$ over 5 years.

Conflict of interest The authors do not have any disclosable interest 